\title{
The Timing of High-speed Railway Construction Based on Demand Power Source \\ Panpan Du ${ }^{1, a}$
}

${ }^{1}$ School of Economics and Management, Beijing Jiaotong University, No. 3, Shangyuan Cun Beijing, China

appdu14@163.com

*Panpan Du

Keywords: High-speed railway; Transportation demands; Time value; Construction time

\begin{abstract}
Historically, the generation and development of transport has a great relationship with its actual demands. In this paper, the causes of high-speed railway production and development in China are discussed from four aspects: passenger demand, enterprise development demand, social sustainable development demand and national strategic demand from the perspective of demand power source, using macroeconomic analysis method. In conclusion, we think the emergence and development of high-speed railway in China is to adapt to the practical demands, and its rapid development has certain inevitability and necessity.
\end{abstract}

\section{基于需求动力源的我国高铁建设时机研究}

\author{
杜盼盼 $1, a$ \\ 1北京交通大学经济管理学院, 海淀区, 北京, 中国 \\ appdu14@163.com \\ "杜盼盼
}

关键词: 高铁; 运输需求; 时间价值; 建设时机

中文摘要: 历史上, 交通工具的产生和发展都和其存在的现实需求的推动有很大关系。本文 从需求动力源的角度, 分别从客运需求、企业发展需求、社会可持续发展需求、国家战略需 求四个方面论述了我国高铁产生和发展的原因, 认为我国高铁的产生和发展是适应了现实需 求, 其快速发展具有一定的必然性和必要性。

\section{1. 引言}

人的生产和生活方式的需要是人创造交通的动力之源, 驱使人类去改革、发展社会交通 ${ }^{1}$ 。 在远古时期, 人们为了生存的需要必须从一个地方到另一个地方寻找生存条件, 于是出现了 简单的代步工具, 如畜力车、独木舟等。随着生产力的发展, 人们有了交换的需要, 交换的 目的是为了满足不同的生活需求, 于是出现了手推车等简单的交通工具。随着生产的发展和 社会的进步, 人们对交通有了更高的需求, 1886年第一辆汽车的诞生改变人们传统的 “行” 的方式，个人交通运输也进入了新纪元。近代我国第一条实用性铁路——唐胥铁路的产生是 为了满足自强立国的需求。可以说任何交通工具的产生和发展与它所存在的现实需求的推动 作用有很大关系。 
自2008年第一条高铁——京沪高铁开通以来, 我国高铁的客运量呈逐年上升的趋势, 2015 年客运量达到了 96139 万人, 占铁路客运量的 $37.9 \%$, 如表1所示。根据中国铁路总公司公布的 数据, 2014 年京沪高铁运送旅客突破 1 亿人次, 比去年同期增长 $27 \%$, 并实现盈利目标。截止 到2016年9月 10 日, 郑徐高铁开通后, 中国高铁运营总里程已突破 2.1 万公里, 是世界上高铁 建设运营里程最长且在建规模最大的国家, 我国高速铁路网已初步形成。

表 1 我国高速铁路客运情况

\begin{tabular}{ccccccc}
\hline 年份 & $\begin{array}{c}\text { 营业里程 } \\
\text { (公里) }\end{array}$ & $\begin{array}{c}\text { 占铁路营业 } \\
\text { 里程比重 }(\%)\end{array}$ & $\begin{array}{c}\text { 客运量 } \\
\text { (万人) }\end{array}$ & $\begin{array}{c}\text { 占铁路客运 } \\
\text { 量比重 }(\%)\end{array}$ & $\begin{array}{c}\text { 旅客周转量 }(\text { 亿公里) } \\
\text { 人 }\end{array}$ & $\begin{array}{c}\text { 占铁路客运周 } \\
\text { 转量比重 }(\%)\end{array}$ \\
\hline $\mathbf{2 0 0 8}$ & 672 & 0.8 & 734 & 0.5 & 15.6 & 0.2 \\
$\mathbf{2 0 0 9}$ & 2699 & 3.2 & 4651 & 3.1 & 162.2 & 2.1 \\
$\mathbf{2 0 1 0}$ & 5133 & 5.6 & 13323 & 8.0 & 463.2 & 5.3 \\
$\mathbf{2 0 1 1}$ & 6601 & 7.1 & 28552 & 15.8 & 1058.4 & 11.0 \\
$\mathbf{2 0 1 2}$ & 9356 & 9.6 & 38815 & 20.5 & 1446.1 & 14.7 \\
$\mathbf{2 0 1 3}$ & 11028 & 10.7 & 52962 & 25.1 & 2141.1 & 20.2 \\
$\mathbf{2 0 1 4}$ & 16456 & 14.7 & 70378 & 30.5 & 2825.0 & 25.1 \\
$\mathbf{2 0 1 5}$ & 19838 & 16.4 & 96139 & 37.9 & 3863.4 & 32.3 \\
\hline
\end{tabular}

资料来源: 《中国统计年鉴2016》

可以说我国高铁在最近十年内获得了快速的发展, 目前国内大量研究对高铁建设的经济 效果做出了研究(林晓言, 2015 ; 周昊, 2013; 覃成林, 2013 )。那么我国的现有需求是否支 持高铁的发展? 需求和高铁建设时机之间存在着怎样的关系? 因此, 本文将从需求经济的角 度定性地分析我国高铁快速发展的原因。

\section{2. 需求动力源理论基础及机理分析}

经济学家约瑟夫・熊彼特曾指出: “生产从一开始就是为了需求, 因为需求才是生产的最 终目的”。在经济学研究中, 运输需求理论是从微观经济学的消费者需求理论中发展而来的。 陈贻龙（1999）、荣朝和（2002）等学者认为运输需求是社会经济生活中人与货物空间位移 方面所提出的有支付能力的需要。在这些理论的基础上, 吴群琪, 马暕（2004）从宏观经济 学的角度对运输需求做了重新定义, 认为运输需求是客观存在的, 运输需求的本质是一切有 利于国民经济及社会发展的对人与物的位移的需要。通过上述对运输需求概念的认识我们认 为运输需求是一切人和物位移的需要, 从需求的无限性和多样性来讲, 一切有利于国民经济 及社会发展的运输位移需要都属于运输需求的范畴。从需求的根本属性来讲, 运输供给的根 本目的是为了最大限度的满足客观存在的需求, 运输需求的存在是运输供给不断改善的动力。

运输需求是与国民经济和社会发展相伴随的需求，因此运输需求也是一种派生性需求， 但这种派生性和其客观存在性并不矛盾。运输需求的派生性是指人们不会单纯为了位移本身 而去位移，运输需求是人们达到某一目的必须手段，而这种需求是主动的、必须的。

运输需求作为一种驱动力伴随着人类经济发展历史的全过程, 其存在也必然蕴含一定的 机理。首先, 运输需求是人类经济发展的需要。虽然运输活动对经济发展具有引导作用, 但 其实现还是要以人们的需求为主要依据。运输供给条件的改善也应当符合运输需求的需要, 这样才能实现布局合理的运输基础设施配置。其次, 从运输需求出发可以弥补运输供给的滞 后性不足。运输供给作为基础设施建设投资成本大, 沉没成本高, 相对于运输需求变化具有 一定的滞后性。因此运输供给要以运输需求的变化规律为决策依据, 弥补运输供给滞后性的 缺陷, 做出正确的决策, 避免资源的浪费。

综上所述, 将高铁看做是一种商品, 从其使用价值看, 高铁需求不仅来自于消费者的位 移需求, 更来自于有赖于交通设施改善对国民经济和社会发展带来巨大外部效益的国家战略 需求, 从其价值属性看, 对高铁的需求就转变成了企业的经营发展需求, 所以说高铁的需求 更是一种广义的需求。林晓言等 (2014) 2将广义需求分为市场需求、政府或军事需求、企业

${ }^{2}$ Xiaoyan Lin, Juan Chen, Hongmei Wang, Lihua Guo. Technical economics [M].2014,5,1 Edition, p53 
经营发展需求及社会需求等。本文根据我国国情和具体情况, 将高铁需求动力源分为客运需 求、企业经营发展需求、社会可持续发展需求和国家战略需求四个方面进行分析。

\section{3. 我国高铁建设时机与需求的关系}

在社会经济发展的不同阶段，人们对交通工具服务特性的要求不同，故在客观上每种交 通工具均有其适应的社会经济发展阶段。高速铁路的建设时机对其充分发挥效益极为重要, 高铁能否取得良好的社会经济效果, 关键在于其是否在适宜的社会经济发展阶段投入运营, 是否契合了现有的需求。

\section{1 客运需求}

需求量是产生运量的前提条件, 运量是需求量得以实现的结果。运量的变化趋势在一定 程度上也反映了需求量的变化趋势, 因此本文选择实际运量来反映人们出行的意愿。改革开 放以来, 我国经济快速发展, 人均GDP不断提高, 社会客运量也在不断上升, 而且表现出几 乎一致的增长趋势, 如图3所示。可以说, 人均GDP和社会客运量之间是有一定关系的, 即人 均GDP越高，物资流动和人员交流的越频繁，运输需求越大。

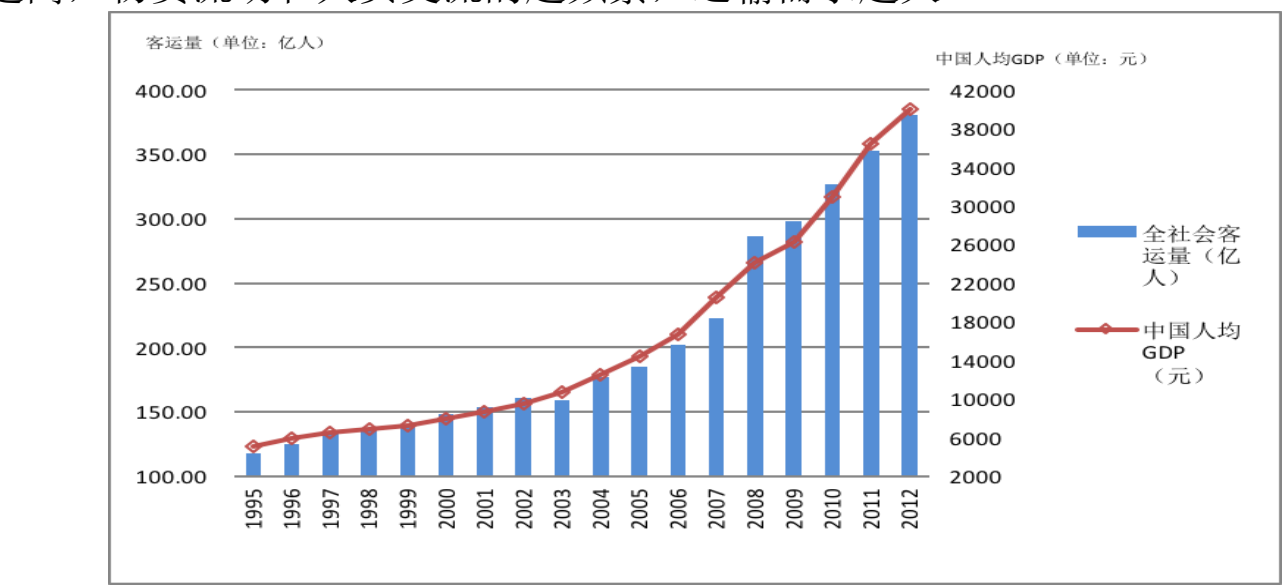

数据来源: 中国统计年鉴

图1 我国全社会客运量和人均GDP的关系

另一方面, 经济的不断发展, 人们更加注重工作效率, 时间观念不断加强, 对旅行速度 的要求也会越来越高, 在距离一定的情况下, 速度越快, 节省的时间越多。不同收入群体, 其时间价值也不同，时间价值指由于时间的节省或延误（荣朝和，2011） 3、以及机会的把握 或丧失而可能导致相关主题的机会收入或损失（荣朝和，2014）。宗芳（2009）对时间价值 的计算方法进行了概括, 主要有生产法 (以GDP为指标), 收入法 (以居民个人年收入为指 标），非集计Probit模型（效用函数法）。由于本文是从宏观层面进行分析，因此选择国民平 均水平以方便国家间的对比, 考虑到各国数据的可得性, 本文选取居民人均可支配收入指标 作为时间价值的评价标准, 即居民人均可支配收入越高, 其时间价值越高。综观世界各国高 速铁路的发展历史, 考虑到欧洲国家和亚洲国家的不同特点, 本文主要以日本、韩国修建高 速铁路的历史数据来预测我国在高铁客运需求方面的平均支付能力。中国第一条运营速度 $300 \mathrm{~km}$ 的高速铁路京津城际于 2008 年 8 月 1 日通车，此时我国人均可支配收入为 3548.43 美元， 高于1964年的日本和 2004 年的韩国, 每公里票价 0.42 元, 大约是日本票价的 $1 / 3$, 韩国票价的 $2 / 3$, 如表2所示。因此, 不论是需求意愿还是支付能力方面, 中国均具有建设高速铁路的条 件, 和国外很多国家一样, 我国高铁的发展也是在人口密集、经济发达的地区率先首先建成 通车，然后才由点到线再到网地逐渐发展起来。 
表2 亚洲主要国家高铁开通历史数据

\begin{tabular}{|c|c|c|c|c|c|}
\hline 国家 & 线路 & 开通时间 & 运营速度 & 每公里票价（元） & $\begin{array}{c}\text { 居民人均可 } \\
\text { 支配收入 (美元) }\end{array}$ \\
\hline 日本 & 新干线东京一大阪 & 1964 & 200 & 1.24 & 835.66 \\
\hline 韩国 & KTX首尔－釜山 & 2004 & 300 & 0.63 & 2436.79 \\
\hline 中国 & 京津城际高铁 & 2008 & 300 & 0.42 & 3548.43 \\
\hline
\end{tabular}

数据来源: 世界银行数据库

在我国高铁开通之后, 高铁客运量一直呈上升趋势, 占铁路客运量比重和全社会客运量 比重也在逐年增大, 而且在高铁开通后, 普通铁路和民航的客运量均呈上升趋势, 并没有因 为高铁的开通客运量发生减少。民航的客运量每年的增长率大概保持在 $10 \%$ 左右，与高铁开 通前平均每年 $11.5 \%$ 的增长率相差不大。如图3、图4所示。

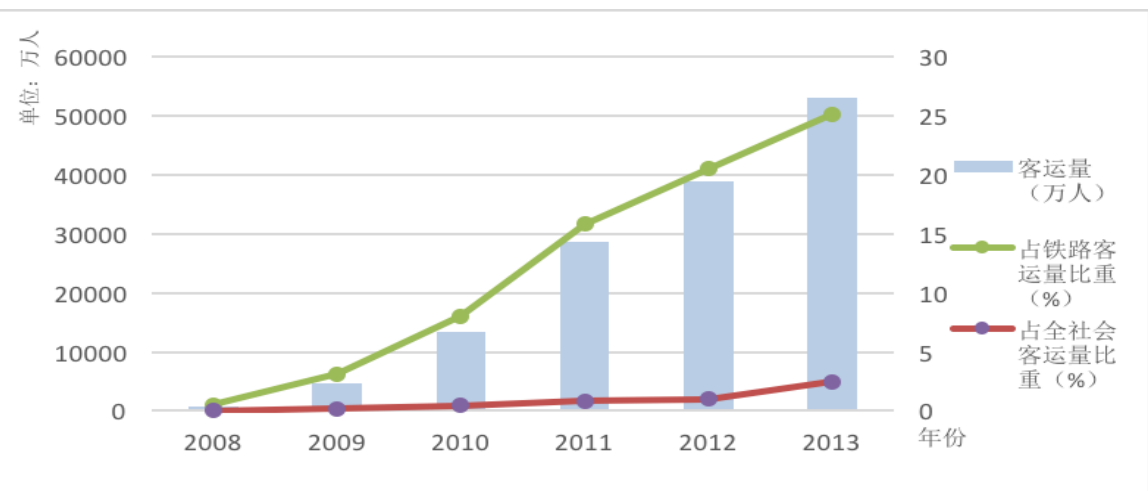

数据来源: 中国统计年鉴

图3 我国高铁客运量变化情况

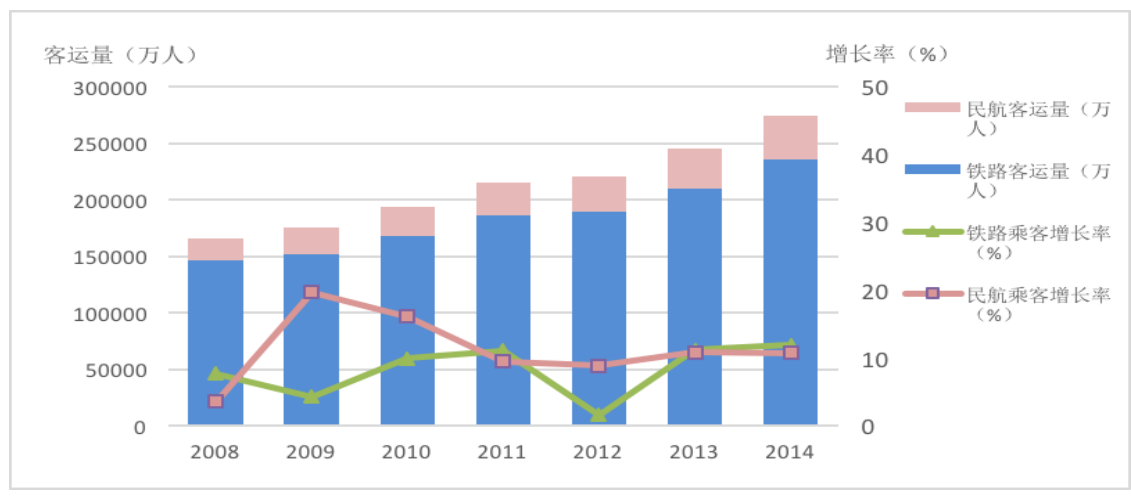

数据来源: 中国统计年鉴

图4 民航和铁路客运量变化情况

综上, 不论是需求意愿还是支付能力方面, 中国均具有建设高速铁路的条件, 高铁的出 现满足了现实的运输需求以及潜在的运输需求, 释放了部分货运能力, 缓解了铁路行业的运 能不足现象。

\section{2 企业发展需求}

高速铁路相对于普通铁路具有载客量大、行驶速度快、安全性好、正点率高、舒适便捷、 能源消耗低等技术经济优势。在企业持续发展发面, 随着我国经济的快速发展, 市场体制不 断完善, 铁路行业曾经享有的垄断地位逐渐消失, 客货运输水平不高, 导致与其他运输方式 竞争时失去不少市场, 因此铁路行业要加快技术创新, 围绕铁路提速、高速、安全及装备现 代化方面，加强科研攻关，提高市场竞争力（王婷婷，2010；王大江，2006）。

从企业家精神来说，每个企业都有一种理念，一种文化，企业家以这种理念和文化来激 
励自己, 为了企业的持续发展, 每个企业家都有创新的需求, 因此以中国中车为代表的铁路 相关企业, 从自身发展角度来说, 是有研发高速动车组的需求的, 并通过创新进一步增强自 身的实力。汪涛等 (2014) 、延平 (2016) 都验证了这一观点, 认为中国中车用创新连通了 世界，实现了从跟随到领跑的创新格局，担当起中国高铁的主力军。

\section{3 社会可持续发展需求}

铁路作为国民经济命脉, 在经济发展中占有重要地位。我国作为发展中国家, 自改革开 放以来, 经济发展取得了重大成绩, 但同时也面临着人口众多、自然资源短缺、环境污染严 重等问题, 因此实现经济、社会、环境、能源的可持续发展是我国必须要解决的首要问题, 这也要求我国应对保护环境与资源的交通运输方式给予鼓励。铁路尤其是高速铁路作为低能 耗、低排放、高效率的运输方式，在可持续发展的诉求下有先天的优势。铁路的耗能系数远 低于其他交通方式, 而高速铁路的能耗比普通铁路还低, 高速铁路每人每公里燃料消耗是汽 车的 $1 / 3$, 是中程客运飞机的 $1 / 5^{4}$ 。赵丽缦（2013）、段满珍（2012）等从高铁的能源利用、 环保设计等角度论证了高铁的节能与环保问题, 认为高铁不仅能带动沿线区域经济的发展, 还节约能源、绿色环保。

所以说，高铁的技术经济特征和我国社会可持续发展要求是契合的，中国继续发展高铁 建设是必然趋势，也为我国高铁建设由点到轴再到网的发展打下了基础。

\section{4 国家战略需求}

国家的支持在高铁的四纵四横规划的实现以及八纵八横规划的实施中发挥着很重要的作 用。中国高铁的建设契合了国家“一带一路”、高铁走出去、城市化等战略。“一带一路”战略 对密切中国同中亚、南亚周边国家以及欧亚国家之间的经济贸易关系, 深化区域交流合作, 维护周边环境, 拓展西部大开发, 具有重大意义。

在 “一带一路” 战略中, 建设丝绸之路经济带关键是互联互通, 其中一项重要的内容就 是以交通基础设施为突破, 推动铁路基建产业链。高铁以其高速、快捷、安全舒适、环保等 技术经济优势成为打通“一带一路”互联互通的重要选择。通过推行高铁“走出去”战略打开国 际市场带动国内相关产业升级和区域格局优化，战略意义重大，同时这也与我国“一带一路” 战略不谋而合。在城市化方面, 尽管高铁站区开发、高铁新城建设暴露出了一些问题, 但依 然作为城市发展的新增长点受到推崇。高铁的建设将有效促进城市群的崛起, 推动高铁沿线 城市化带的形成，对构建城市化战略布局有重要作用（卢周来，2011；㚞桦，2011）。

\section{4. 结论}

社会的进步与交通运输的发展是密切相关的, 经济的发展离不开运输条件的进步。本文 从需求动力源的角度, 分别从客运需求、企业发展需求、社会可持续发展需求、国家战略需 求四个方面论述了我国高铁产生和发展的必然性和必要性。

高速铁路作为现代交通工具，其产生和发展满足客运需求是根本。我国国土辽阔，人口 众多, 经济快速发展, 社会客运量不断上升, 这些都为高铁的产生提供了需求市场, 而企业 发展需求又为高铁的产生提供了技术和资金的支持, 社会可持续发展需求和国家战略需求又 使高铁实现“点——轴——网”的发展目标成为可能。可以说, 现实存在的需求推动了我国高 铁的产生和发展, 进一步推动了社会运输系统的完善。

另一方面，高铁的发展促进了经济发展，产生了巨大的外部效益，进一步经济的发展又 促进了社会物质和生活交流的频繁, 刺激了更大的需求。运输需求和经济的发展表现出螺旋 上升的相互促进关系, 为了更好的促进这种良性循环, 保持高铁的良性发展, 发挥高铁的网 络效应, 我国应当重视高铁的统一规划、布局、建设, 避免重复建设和资源浪费, 确定高铁

\footnotetext{
${ }^{4}$ Xiaoyan Lin et al. High speed railway and the new pattern of economic and social development [M]. Sciences Academic Press, 2015,7: p64
} 
发展的合理速度, 有序推进高铁建设, 同时加强高铁的盈利能力, 制定合理票价, 提供高质 量的服务，保证高铁旅客量。

\section{References}

[1]Chaohe Rong. The Value of Transport-logistics Time and Its Applications in Time-spatial Analysis [J]. Economic Research Journal,2011,08:133-146.

[2]Chaohe Rong. The Fundamental Function of Time-Spatial Analysis in Economic Research [J]. Journal of Beijing Jiaotong University Social Sciences Edition,2014,04:1-11.

[3]Deyang Li, Mingfang Gao, Yuanjun Cheng et al.The Sociology of Transportation[M]. Beijing:

China Social Sciences Publishing House; 2012, page:31

[4]Xiaoxun Gao. "Technology Push" or " Demand Pull" : an Argument on the Motivation of Technological Innovation [J]. Technology and Innovation Management,2011,32(6):590-593

[5]Xiaoyan Lin, Juan Chen, Hongmei Wang, Lihua Guo. Technical economics [M].2014,5,1 Edition, p53

[6]Chaohe Rong. Western Transportation Economics[M].Beijing: Economic Science Press,2002.

[7]Yilong Chen, Zhenyi Shao. Transportation Economics.[M] People traffic press, 1999:143-144,147-151

[8]Fang Zong, Zhicai Juan. Calculation and Application of Value of Travel Time [J]. Journal of Transportation Systems Engineering and Information Technology,2009,9(3):114-119.

[9]Tingting Wang. Railway transportation enterprise management innovation [J]. Developing,2010,(1):96-96.

[10]Dajiang Wang, Qipeng Yan, Ding Luo. Management strategy of railway transportation enterprises under competitive conditions [J]. Transportation Enterprise Management,2006,21(9):55-56.

[11]Tao Wang, An Wang, Gongcheng Wang. Technology innovation of research China CSR [J]. Enterprise Management,2014,(10):96-98.

[12]Xiaoyan Lin et al. High speed railway and the new pattern of economic and social development

[M]. Sciences Academic Press, 2015,7: p64

[13]Qunqi Wu. Reunderstanding of the theory of transportation demand [J]. Comprehensive Transportation,2004,(3):8-11.

[14]Manzhen Duan, Bo Dong. Resistance and the Inevitable Trend of China High-speed Rail Development [J]. Urban Research,2012,27(10):94-98.

[15]Kaifeng Zheng, Haitao Shao, Jiajia Hao. The Significance and Measures for the Globalization of China's High Speed Railway Overview of the Speeches of the Guest Speakers at the Summit on the Globalization Strategy of China's High Speed Railway [J]. Journal of Southwest Jiaotong University（Social Science Edition）,2014,15(1):1-7.

[16]Xiaotong Zhang. China's high-speed rail "going out": achievements, problems and Countermeasures [J]. International Economic Cooperation,2014,0(11):26-29.

[17]Nelson R. The Economics of invention: a survey of the literature [J]. The Journal of Business, 1959.

[18]Roberts E D. Management of research, development and technology based innovation[M]. Cambridge: the MIT Press, 1999 